\title{
UM MÉTODO DE SUPORTE A DECISÕES SOBRE INVESTIMENTO E COMERCIALIZAÇÃO DE ENERGIA ELÉTRICA NO BRASIL
}

\author{
Roberto Castro* \\ castro@cpfl.com.br
}

\author{
Christiano Lyra Filho ${ }^{\dagger}$ \\ chrlyraedensis.fee.unicamp.br
}

${ }^{*}$ CPFL ENERGIA - Estrada Campinas - Mogi Mirim , $\mathrm{km} 2,5$ - Bloco III $2^{\circ}$ andar

CEP 13088-900 - Caixa Postal 1408 - Campinas - SP

Tel.: (xx19) 37568124 - Fax: (xx19) 37568828

\author{
${ }^{\dagger}$ UNICAMP/FEEC/DENSIS \\ Faculdade de Engenharia Elétrica e de Computação da Universidade Estadual de Campinas - UNICAMP \\ CEP 13081-970 - Caixa Postal 6101 - Campinas - SP \\ Tel.: (xx19) 37883775 - Fax: (xx19) 37883775
}

\begin{abstract}
This paper presets a decision making method for investments, trading and portfolio evaluation on electrical energy in the wholesale Brazilian trading market. Scenarios for spot prices are estimated on mid-term horizon by a statistic approach. The probability curve of pay-off for several alternatives of trading is calculated. Risk aversion of the decision maker is introduced in the process by multicriteria optimization approach, so that decision support is carried out by the method according to specific decision maker risk sensitivity. A case study illustrates application of the methodology for decision making on trading electrical energy by a distribution utility, for a two-year horizon.
\end{abstract}

KEYWORDS: Spot price estimation, energy trading, market risk, decision making theory, multicriteria optimization.

\section{RESUMO}

Este trabalho propõe um método de suporte a decisões de investimento, contratação e de avaliação de portfolio de ativos

Artigo submetido em 10/12/03

1a. Revisão em 11/04/05

2a. Revisão em 02/11/05

Aceito sob recomendação do Ed. Assoc. Prof. Glauco Taranto de energia elétrica na comercialização em atacado no Brasil. A metodologia apresentada utiliza processo estatístico para estimativa do preço da energia no mercado de curto prazo, através do qual constroem-se cenários de preços futuros. As probabilidades associadas a cada cenário de preço definem a função densidade de probabilidade para os resultados financeiros esperados pelos agentes, os quais estão associados às suas decisões e conseqüentes tomadas de posição diante do mercado. A aversão que o agente apresenta diante do risco é caracterizada a partir da aplicação de conceitos de otimização multiobjetivo e determinação aproximada de soluções eficientes do problema. Um estudo de caso ilustra a aplicação da metodologia na definição da melhor alternativa de contratação de energia para um agente de distribuição em horizonte de dois anos.

PALAVRAS-CHAVE: Estimativa de preço, comercialização de energia, risco de mercado, teoria da decisão, otimização multicritério

\section{INTRODUÇÃO}

A energia elétrica passou a ser tratada como mercadoria passível de livre comercialização a partir da década de 90 , quando diversos países desregulamentaram seus setores elétricos, até então monopólios estatais ou tratados com forte 
regulamentação, para impedir a interferência das regras de mercado no setor.

Por muitos anos, os economistas defenderam que a energia elétrica era um monopólio natural, pois do ponto de vista da racionalidade econômica, pelo fato da transmissão e distribuição representarem elevados investimentos, estes sistemas não são construídos simultaneamente por dois agentes que concorrem pelo atendimento à mesma parcela de mercado.

Mais recentemente, a percepção de que é possível a competição entre os agentes na área de produção e comercialização da energia, mantendo-se o monopólio natural apenas nas áreas de transmissão e distribuição (Davidison et al, 2002) permitiu que as leis de mercado passassem a permear o serviço público de energia elétrica.

O processo de abertura do setor elétrico ocorreu como uma tendência mundial, iniciando-se na Inglaterra (Green \& Newbery, 1992) e na Nova Zelândia. Em seguida, após vários anos, na Suécia (Anderson \& Bregman, 1995), Noruega (Amundsen et al, 1994), Austrália (Brennan \& Melaine, 1998) e em algumas áreas dos Estados Unidos, como New England e New York (NY ISO - on line), Califórnia (Californian ISO - on line), Pennsylvania, New Jersey e Maryland (PJM - on line).

A característica fundamental, comum a todos os processos nos diversos países é a introdução do processo de tomada de decisões através de mecanismos de mercado, em substituição aos métodos tradicionais, típicos de sistemas fortemente regulados (Vázquez et al, 2002). Embora várias teorias econômicas defendam que a existência de um mercado de curto prazo (spot) com preços praticados pelas leis de mercado seja suficiente para sustentar as decisões para investimentos na expansão da oferta de energia (Caramanis, 1982; PerezArrigara \& Meseguer, 1997), várias dificuldades aparecem na prática. Para tratar essas dificuldades e propiciar o ambiente favorável ao crescimento sustentado da oferta de energia, a desregulamentação do setor elétrico enfrenta um desafio comum: estabelecer regras claras, atrativas aos investidores quanto a redução dos riscos, mas simultaneamente, sustentada pelas regras básicas de mercado livre.

Até a aprovação do código de águas (Bibl. Do Exército, 1978; Código de águas, 1934), em 1934, onde se estabeleceu que a concessão de serviços públicos de energia elétrica passava a ser direito restrito de brasileiros, ou de empresas constituídas no Brasil, os investimentos no setor elétrico brasileiro eram feitos em sua maior parte, pela iniciativa privada multinacional. Naquele período utilizava-se a "cláusula ouro"(Cláusula ouro, 1933), dispositivo constitucional que permitia que as empresas do setor elétrico brasileiro recebessem em ouro, parte de suas receitas, auferidas pela atividade no setor elétrico brasileiro. O metal era comercializado no mercado internacional e facilmente convertido em dólar.

Com a extinção da "cláusula ouro", na tentativa do governo brasileiro fortalecer a economia do País, nenhum pagamento em território Nacional pode ser feito em outra moeda que não a moeda oficial brasileira. Dessa maneira, os investidores internacionais ficaram sem a proteção contra as flutuações da moeda brasileira, um risco a que todos os investidores estão expostos quando fazem negócios fora de seus países de origem.

Os investidores internacionais reduziram seus investimentos no setor elétrico brasileiro e as atividades passaram às mãos do Estado entre as décadas de 1950 e 1990. Entre 1990 e 2002, com o processo de privatização, parte significativa das empresas de distribuição, representada por cerca de $80 \%$ de toda a energia distribuída, e uma parcela das empresas geradoras, cerca de $20 \%$ da energia gerada no país, foi vendida para a iniciativa privada (Paixão, 2000).

Atualmente, a propriedade no setor elétrico é híbrida, o que lhe confere uma relação de conflito entre interesses públicos e privados, além das demais dificuldades inerentes ao setor, representadas pelos riscos de mercado que sujeitam indistintamente as empresas estatais ou privadas. Neste cenário, definir um arcabouço regulatório e um ambiente capaz de atrair investimentos no setor elétrico, como está sendo implementado pelo atual Ministério de Minas e Energia (MME, 2003), é uma tarefa difícil.

Os agentes no mercado de energia elétrica no Brasil, em qualquer área de atuação no setor, seja na geração, comercialização, distribuição ou mesmo na transmissão de energia, estão sujeitos a processos decisórios sob riscos (Castro, Ramos e Lyra, 1999), representados basicamente pelas incertezas quanto à evolução do consumo de energia elétrica, a capacidade de atendimento à demanda de energia e aos preços.

Esses riscos existem em qualquer mercado de energia no mundo, mas particularmente em sistemas com predominância em hidroeletricidade, como é o caso do sistema brasileiro. Os investidores em empreendimentos hidrelétricos estão sujeitos, adicionalmente, à concorrência pelo uso múltiplo da água e das instalações hidrelétricas, que leva a incertezas adicionais em relação ao dimensionamento e ao retorno dos investimentos nos projetos de geração (Castro, 1994; Lyra, Castro \& Ferreira, 1995).

A variação dos preços expõe os agentes aos riscos de baixo retorno dos investimentos em construção de empreendimentos de geração, ou na expansão e manutenção dos sistemas de distribuição de energia elétrica. A busca de proteção ocorre das mais variadas formas, dependendo do perfil de cada agente e de sua aversão ao risco do negócio. 
A contratação bilateral de energia é o instrumento mais utilizado para reduzir os efeitos do risco nos investimentos, pois garante o preço futuro do produto e reduz a exposição das empresas ao preço da energia no mercado de curto prazo. No contrato bilateral, o preço na data de entrega está garantido, tanto para o comprador quanto para o vendedor, os quais se protegem, respectivamente, contra aumentos ou reduções drásticas no preço do produto comercializado.

O processo de tomada de decisão para investimento ou para a comercialização no atacado de energia elétrica, bem como da avaliação do portfolio de ativos de uma empresa, tem particularidades que precisam ser tratadas adequadamente, caso contrário, podem comprometer o retorno dos investimentos em primeira instância, com impacto inevitável sobre o abastecimento de energia, que pode levar a conseqüências danosas para a economia do país.

A aversão a investimentos em condições de alto risco não é uma prerrogativa dos investidores privados. De fato, basta observar-se a situação de inadimplência geral verificada no setor elétrico no início da década de 90, quando mesmo as empresas estatais deixaram de investir na expansão do sistema, em um cenário de endividamento generalizado, com mais de 20 obras de geração paralisadas (Paixão, 2000).

O método de suporte á decisão desenvolvido neste trabalho é um processo de análise e avaliação para tratar os riscos de mercado no setor elétrico brasileiro. A metodologia compõese de três etapas distintas; i) um processo de estimativa e determinação de cenários para o preço da energia no mercado de curto prazo; ii) um sistema para determinar os resultados financeiros obtidos para cada cenário; iii) um módulo de tomada de decisão, onde se integra processos de análise e gerenciamento de risco de mercado com a aplicação dos conceitos relacionados à otimização multiobjetivo, formalismo matemático que permite caracterizar variáveis capazes de traduzir a percepção que o decisor tem sobre os riscos, para estabelecer a hierarquia entre as possíveis decisões.

No próximo item apresenta-se o processo de estimativa do preço da energia e a definição de cenários de preços futuros, onde se descreve as particularidades do setor elétrico brasileiro. O método permite que sejam definidos cenários e determinadas as probabilidades associadas à ocorrência de cada um deles (Castro, R. \& Lyra, C. - 2003).

No Item 3 descreve-se o processo de comercialização de energia no mercado brasileiro e apresenta-se as funções que determinam os resultados financeiros dos agentes de mercado. No Item 4 são apresentados os métodos para avaliação dos riscos, o Item 5 traz a caracterização do problema multicritério, que compõe o módulo de tomada de decisão. No Item 6 apresenta-se um estudo de caso, utilizando dados reais do setor elétrico brasileiro. Seguem-se as conclusões do

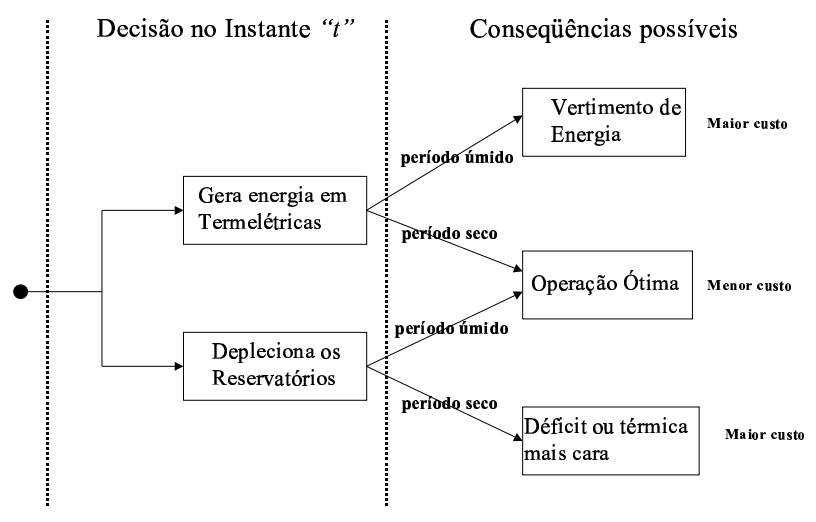

Figura 1: Árvore de Decisão Operativa no Sistema Brasileiro trabalho, no Item 7.

\section{CENÁRIOS DE PREÇO DA ENERGIA NO MERCADO DE CURTO PRAZO}

O custo marginal de operação $(\mathrm{CMO})$ é o custo incorrido pelo sistema gerador quando aumenta-se a produção de energia para atender a um incremento de carga (Castro \& Lyra, 2003). Em situações de sobra de energia, o valor de CMO é baixo, pois a carga adicional poderá ser facilmente atendida com um aumento na geração de usinas hidrelétricas sem capacidade de armazenamento de energia, as chamadas usinas a fio d'água. Nas situações críticas, onde a expectativa de déficit de energia é iminente, o aumento de carga será atendido com a geração de usinas termelétricas, com a conseqüente queima adicional de combustível. O valor de CMO é elevado neste caso e pode atingir o custo do déficit, refletindo a escassez de energia e o "grande esforço"do sistema para atendimento a uma eventual adição de carga .

O custo marginal de operação reflete as condições de atendimento da carga e, portanto, pode ser utilizado como referência do preço da energia no mercado de contratos de curta duração e para o preço da energia na Câmara de Comercialização de Energia Elétrica (CCEE), onde são calculadas e liquidadas as diferenças contratuais (MAE - 2000).

Na Fig. 1, ilustra-se a árvore de decisões envolvidas na operação em um sistema elétrico brasileiro, onde mostra-se que decisões equivocadas podem levar a conseqüências desastrosas para o atendimento à carga, pois o sistema elétrico brasileiro tem "memória", representada pelo armazenamento de energia nos reservatórios das usinas hidrelétricas.

Os contratos de curto prazo são utilizados pelos agentes de mercado como mecanismo de proteção contra as variações no Preço de Liquidação de Diferenças (PLD), especialmente aos agentes que atuam no Ambiente de Contratação Livre 
(ACL). No entanto, a contratação de curto prazo não serve para o atendimento da obrigatoriedade de contratação mínima estabelecida pela legislação para os agentes que atuam no Ambiente de Contratação Regulada (ACR), pois esta exigência deve ser atendida por contratos de longo prazo (com mais de 6 meses de duração), de acordo com a Lei 10.848 de 15 de março de 2004 e do Decreto 5.163 de 30 de julho do mesmo ano.

De acordo com o programa de expansão da geração, utilizado pelo Operador Nacional do Sistema (ONS) no planejamento da operação do sistema, a predominância da geração de energia a partir de usinas hidrelétricas se manterá ainda por muitos anos no sistema brasileiro (ONS - 2005). Na situação atual, mais de $94 \%$ da energia gerada no país é proveniente dessa fonte. No plano de expansão do período 2005 a 2009 , as usinas hidrelétricas representam cerca de $23 \%$ da potência a ser instalada, sendo $77 \%$ a parcela de usinas térmicas.

Se este plano de expansão for cumprido, ao final de 2009 cerca de $59 \%$ da capacidade instalada será de usinas hidrelétricas. Se a partir de janeiro de 2010 não ocorresse a implantação de qualquer usina hidrelétrica, e toda a expansão fosse feita por termelétricas, apenas no ano 2012 a proporção de capacidade instalada em termelétricas seria equivalente à das hidrelétricas.

Assim, pode-se concluir que a disponibilidade de água no sistema, principal componente do Custo Marginal de Operação $(\mathrm{CMO})$, continuará interferindo no preço da energia no sistema ainda por muito tempo e que o preço da energia no mercado de curto prazo continuará dependente da água disponível para geração de energia nas usinas hidrelétricas. $\mathrm{O}$ CMO é utilizado como a melhor aproximação que se pode ter do preço da energia no mercado de curto prazo. No caso do sistema brasileiro, guarda correlação direta com a energia afluente e a energia armazenada nos reservatórios das hidrelétricas. Pode ser calculado a partir de simulações com metodologias baseadas em otimização, como as utilizadas pelas ferramentas computacionais que utilizam programação dinâmica estocástica (Cepel - 1993; Pereira, M.V.F \& Pinto, L.M.V.G - 1991; Martinez - 2001).

Neste trabalho utiliza-se o programa newave para determinar o CMO no horizonte de médio prazo, sistema computacional que se utiliza dos processos de otimização anteriormente citados e que é utilizado pelo ONS para o planejamento da operação do sistema e pela CCEE na determinação do preço da energia no mercado de curto prazo, portanto, representa o método de cálculo adotado pelo setor elétrico brasileiro. Destaque-se no entanto, que as idéias propostas neste trabalho podem ser associadas a metodologias alternativas de planejamento da operação, do cálculo do custo marginal de operação e determinação do preço da energia.

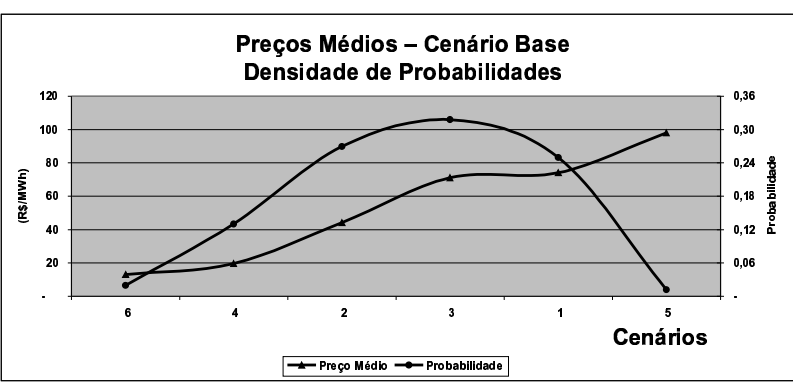

Figura 2: Cenários de Preços - Caso Base ONS



Figura 3: Cenários de Preços - Caso Alternativo

\subsection{Probabilidades Associadas aos Ce- nários de Preços}

Num exemplo de aplicação do método de estimativa dos preços da energia no mercado, determina-se a expectativa de preços para um conjunto de seis cenários possíveis, utilizando-se o programa newave. Considera-se duas possibilidades de expansão da oferta e evolução da demanda de energia. No primeiro caso, considerando-se o cenário de oferta e demanda do caso base do ONS (ONS, 2003), os cenários de preços e as probabilidades associadas estão apresentadas na Fig. 2.

Se houver uma retração nos investimentos para expansão da oferta, com conseqüente atraso no cronograma das obras de geração, e o mercado de energia elétrica retomar seu crescimento em ritmo mais acentuado do que se espera nas previsões, os cenários de preços da energia terão a característica representada na Fig. 3.

Observe-se que nesse cenário alternativo de oferta e mercado é mais elevada a probabilidade de preços altos de energia no mercado de curto prazo.

Usualmente no setor elétrico brasileiro procede-se à análise estocástica sobre a afluência de energia às usinas hidrelétricas, mantendo-se a demanda e o plano de expansão como determinísticos. 
A análise estocástica de energia afluente é feita a partir da reprodução das séries históricas através de séries sintéticas de energia afluente (Cepel, 1993), as quais preservam a média (MLT - Média de Longo Termo) e o desvio padrão das séries históricas originais.

Em geral são utilizadas duas mil séries sintéticas para reproduzir a aleatoriedade da energia afluente e considera-se que a probabilidade de ocorrência de cada série seja a mesma.

No método de estimativa do preço de curto prazo proposto neste trabalho, busca-se reduzir o número de cenários simulados, agregando-se no entanto, a informação de que cada cenário tem diferente probabilidade de ocorrência.

O método de suporte à decisão desenvolvido pode utilizar qualquer quantidade de cenários de preços para a energia elétrica, entretanto, a redução no número de cenários permite que técnicas de otimização estocástica (Kall \& Wallace, 1994) sejam futuramente implementados para a solução do problema. Com um elevado número de cenários, a utilização de programação estocástica fica comprometida.

\subsection{Cálculo da Função Densidade de Pro- babilidade do Custo Marginal de Ope- ração}

As energias afluentes aos reservatórios equivalentes dos submercados são usualmente consideradas em termos do percentual que representam sobre a Média de Longo Termo (MLT) de todas as energias afluentes conhecidas do histórico de vazões.

Calcula-se o valor da MLT das energias afluentes em cada submercado do sistema, de acordo com a equação (1). Em seguida, determina-se que percentual desta MLT é representada por cada série de energia afluente considerada, entre as 2000 séries sintéticas, de acordo com a equação (2).

$$
\begin{gathered}
M L T \_E A F L_{s, a n o, m}=\frac{\sum_{k=1}^{n s e ́ r i e s} E A F L_{s, a n o, m, s e ́ r i e}}{n s e ́ r i e s} \\
E A_{s, a n o, \text { série }, m}=\frac{E A F L_{s, a n o, m, \text { série }}}{M L T \_E A F L_{s, \text { ano }, m}} * 100
\end{gathered}
$$

Onde:

- MLT_EAFL $L_{s, a n o, m}$ é a Média de Longo Termo da energia afluente ao submercado $s$ no ano ano e no mês $m$ [Mwmed];
- $E A F L_{s, a n o, m, s e ́ r i e}$ é a energia afluente ao submercado $s$ no ano ano, mês $m$ e série série [Mwmed];

- EA $A_{s, a n o, s e ́ r i e, m}$ é o percentual que a energia afluente representa da MLT no submercado $s$, ano ano, série série e no mês $m(\%)$;

- nséries é o número total de séries sintéticas utilizadas [adimensional].

Nesta abordagem caracteriza-se o valor de MLT como a média da energia afluente das séries sintéticas consideradas nas simulações, ao invés de se utilizar da definição típica de MLT (média dos valores históricos conhecidos). Esta opção foi adotada para simplificar a entrada de dados no programa computacional utilizado nos cálculos - ela evita que o usuário seja obrigado a calcular o valor de MLT de cada mês do histórico e forneça este parâmetro como dado de entrada (o programa calcula a MLT das séries sintéticas simuladas para cada mês). Como as séries sintéticas são geradas a partir do histórico de vazões para um modelo auto-regressivo de ordem "p", as séries geradas são estatisticamente equivalentes ao histórico (Cepel, 1993). Portanto, não há diferença significativa entre a MLT calculada para as séries sintéticas e a MLT calculada para o histórico.

Determinada a variável definida em (2), calcula-se sua distribuição em "n" intervalos de percentuais da MLT previamente definidos, conforme a equação (3).

$$
i n t \_E A=\frac{L s u p \_E A-L i n f \_E A}{n \_i n t \_E A-1}
$$

Onde:

- int_EA é o tamanho do intervalo de energia afluente sobre o qual serão distribuídos todos os valores das séries sintéticas utilizados na simulação da operação do sistema [\%];

- Lsup_EA é o máximo valor de percentual da MLT que será considerado para a energia afluente aos submercados - este valor é definido pelo usuário [\%];

- Linf_EA é o mínimo valor de percentual da MLT que será considerado para a energia afluente aos submercados [\%] - este valor é pré-definido, tendo-se em vista o menor valor para o qual se deseja efetuar análise sobre a energia afluente aos reservatórios (na implementação deste trabalho adotou-se 30\%).;

- $n \_i n t \_E A$ é o número de intervalos sobre os quais serão distribuídas as energia afluentes aos submercados [adimensional] - este valor é pré-definido com base no 
número mínimo de intervalos de discretização da energia afluente que permita a determinação consistente de sua função densidade de probablidades (na implementação deste trabalho considerou-se que 40 intervalos são suficientes para representar essa função).

Os limites inferiores e superiores de cada intervalo " $k$ ", utilizado na discretização da energia afluente, são calculados através das equações de (4) a (10), apresentadas a seguir.

se $k=1$ :

$$
\begin{aligned}
& L i n f \_i n t \_E A(k)=L i n f \_E A \\
& L s u p \_i n t \_E A(k)= \\
& \quad i n t \_E A+L i n f \_i n t \_E A(k)
\end{aligned}
$$

se $k>1$ :

$$
\begin{gathered}
\text { Linf_int_EA(k)= } \\
\text { Lsup_int_EA(k-1) } \\
\text { Lsup_int_EA }(k)= \\
\text { int_EA+Linf_int_EA(k) } \\
k=1,2,3, \ldots,\left(n \_i n t \_E A-1\right)
\end{gathered}
$$

Onde:

- Linf_int_EA(k) é o limite inferior do percentual de energia afluente no intervalo de discretização $k$ [\%];

- Lsup_int_EA(k) é o limite superior do percentual de energia afluente no intervalo de discretização $k$ [\%];

Identifica-se a qual dos intervalos de discretização pertence cada valor de $E A_{s, a n o, s e ́ r i e, m}$. A partir dessas informações, determina-se a função densidade de probabilidade do CMO. Para isso utiliza-se a energia afluente como variável explicativa, através da associação dos valores calculados para o CMO com o correspondente valor de energia afluente.

Definida a distribuição da energia afluente de todas as séries, sobre o intervalo de análise proposto, determina-se quantas e quais são as séries de cada intervalo. A cada série sintética está associado um valor de CMO. Com essas informações calcula-se a probabilidade, o valor esperado, a variância e o desvio padrão do CMO em cada intervalo discretizado, através das equações 11 a 14 a seguir (Castro \& Lyra, 2003).

$$
P(k)_{a n o, m}=\frac{N S(k)_{s, a n o, m}}{n s e ́ r i e s}
$$

$$
\begin{aligned}
& C M(k)_{s, \text { ano }, m}= \\
& \frac{\sum_{n s=1}^{n s e ́ r i e s} a\left[I\left(E A_{s, a n o, n s, m}\right)\right] * C_{s, a n o, n s, m}}{N S(k)_{s, a n o, m}}
\end{aligned}
$$

$$
\frac{\sum_{n s=1}^{V(k)_{s, a n o, m}}\left[C_{s, \text { ano,ns, } m}-C M(k)_{s, a n o, m}\right]^{2} * a\left[I\left(E A_{s, a n o, n s, m}\right)\right]}{N S(k)_{s, a n o, m}}
$$

$$
S D(k)_{s, a n o, m}=\left[V(k)_{s, a n o, m}\right]^{\frac{1}{2}}
$$

Onde:

- $P(k)_{a n o, m}$ é a probabilidade de ocorrência da energia afluente no intervalo de discretização $k$ no ano ano e no mês $m$ - esta é a probabilidade de ocorrência dos valores de CMO no mesmo submercado, ano e mês, para o intervalo de discretização $k$ considerando que a energia afluente é a variável explicativa das ocorrências do CMO [adimensional];

- $C_{s, a n o, m}$ é o valor do CMO no submercado $s$, ano ano e mês $m[\$ / \mathrm{MWh}]$;

- $C M(k)_{s, a n o, m}$ é o valor esperado do CMO no intervalo de discretização $k$, submercado $s$, ano ano e mês $m$ [\$/MWh];

- $V(k)_{s, a n o, m}$ é a variância do CMO no intervalo de discretização $k$, submercado $s$, ano ano e mês $m$ $\left[(\$ / \mathrm{MWh})^{2}\right]$;

- $S D(k)_{s, a n o, m}$ é o desvio padrão do CMO no intervalo de discretização $k$, submercado $s$, ano ano e mês $m$ [\$/MWh];

- $N S(k)_{s, a n o, m}$ é o número de séries que pertencem ap mesmo intervalo de discretização $k$, no submercado $s$, ano ano e mês $m$ [adimensional];

- $a\left[I\left(E A_{s, a n o, n s, m}\right)\right]$ é o indicador que mostra se o valor de $E A_{s, a n o, n s, m}$ pertence ao intervalo I de discretização. Se pertencer, o indicador assume valor 1 , se não pertencer assume valor nulo.

A Fig. 4 apresenta os resultados para um exemplo de aplicação da estimativa do CMO com base na energia afluente aos reservatórios. 




Figura 4: Estimativa de Preço - Energia Afluente como Variável Explicativa do $\mathrm{CMO}$.

\subsection{Custo Marginal de Operação em fun- ção da energia armazenada}

Além da energia afluente, o CMO relaciona-se diretamente com a energia armazenada nos reservatórios. Quanto maior a energia armazenada, mais baixo o custo marginal de operação e vice-versa.

Utilizando-se o mesmo processo de cálculo empregado no item 2.2, com a energia armazenada no sistema como variável explicativa, determina-se a função densidade de probabilidade do CMO em função da energia armazenada do sistema. A Fig.5 apresenta um exemplo desta função.

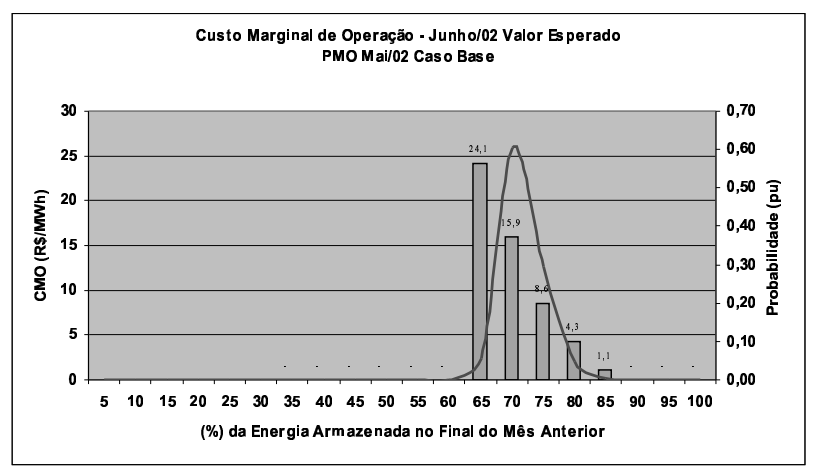

Figura 5: Estimativa de Preço - Energia Armazenada como Variável Explicativa

\subsection{Processo de convolução}

Para estimativa do preço da energia no mercado de curto prazo pode-se utilizar isoladamente a correlação com a energia armazenada ou com a energia afluente. Alternativamente, um processo de convolução entre essas variáveis permite calcular o valor de CMO para cada cenário de energia afluente, dada a energia armazenada no passado, ou seja, levando-se em conta que a energia armazenada é variável dependente da energia afluente.

O programa computacional desenvolvido está preparado para apresentar os resultados de estimativa de preço para qualquer desses métodos, os quais podem ser escolhidos em função da aplicação que se vai fazer dos valores estimados. Para as aplicações práticas do processo de estimativa realizadas até o momento, a utilização isolada da energia afluente como variável explicativa do CMO tem apresentado resultados satisfatórios.

No processo de estimativa de preços em horizonte de médio/longo prazos através da convolução entre a energia armazenada e a energia afluente, avalia-se as probabilidades condicionadas do CMO, para cada ocorrência de energia afluente, considerando-se a energia armazenada no período anterior, a Fig. 6 ilustra a aplicação do método.

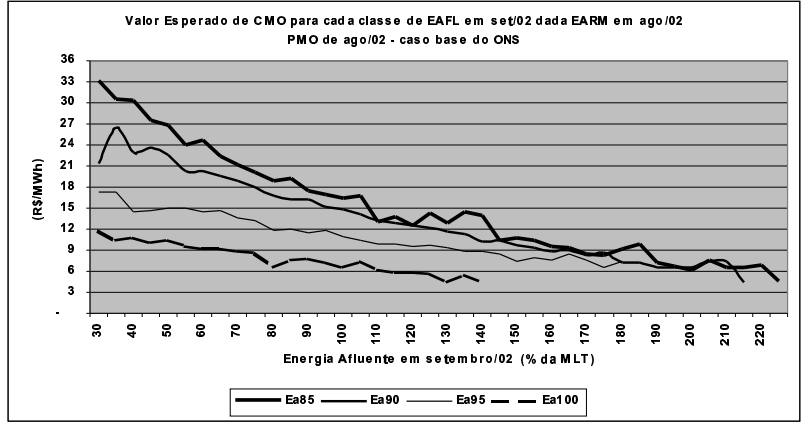

Figura 6: Estimativa de Preço - Convolução entre energia armazenada e energia afluente.

Uma aplicação prática ilustrativa do método de estimativa do preço da energia no mercado de curto prazo levando em conta a energia afluente, armazenada e a convolução entre ambas as variáveis pode ser encontrada em (Castro \& Lyra, 2003).

\section{COMERCIALIZAÇÃO ENTRE EMPRE- SAS}

A regra básica para a comercialização de energia entre empresas no mercado de curto prazo, sob a estrutura vigente no setor, é a consideração da energia gerada e da carga no "centro de gravidade"do submercado em que a energia é gerada ou consumida (MAE, 2000).

O centro de gravidade do submercado é definido sob a hipótese de rateio equânime de perdas. Assim, associa-se à geração e à carga, os fatores de rateio de perdas da rede básica, definidos sob o critério de que metade da energia perdida no sistema de transmissão acima de $230 \mathrm{kV}$ deve ser adicionada à carga verificada no sistema e a outra metade dessas perdas deve ser reduzida da energia gerada. 
Supondo-se que Gef seja o total de geração verificada no sistema e Cef o total da carga, a perda total do sistema será dada por, Pt, definido a seguir.

$$
P t=G e f-C e f
$$

$\mathrm{O}$ fator de perda da geração $(F P g)$ e da carga $(F P c)$ serão calculados respectivamente, pelas equações (16) e (17).

$$
\begin{aligned}
& F P g=(P t / 2) / G e f \\
& F P c=(P t / 2) / C e f
\end{aligned}
$$

A Fig. 7 ilustra o processo de alocação de perdas, através da aplicação dos respectivos fatores, para um sistema composto de apenas 2 barras: uma de geração (g) e outra de carga (c). $\mathrm{O}$ centro de gravidade (cg), no qual são determinados os valores da carga (Ccg) e geração (Gcg), a partir da geração e carga verificadas (respectivamente, Gef e Cef), está ilustrado na figura.

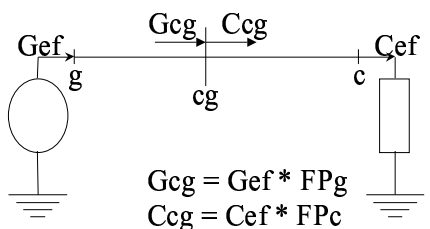

Figura 7: Referência de Geração e Carga ao Centro de Gravidade do Sistema

As perdas de transmissão são calculadas para todo o sistema, de acordo com a equação (15), entretanto, a partir do que ilustra a Fig. 7, observa-se que os fatores calculados fazem a alocação para cada agente individualmente e de forma equânime.

A comercialização de energia no sistema brasileiro é feito no centro de gravidade (cg) de cada submercado, portanto, os agentes individualmente, são obrigados a comercializar uma parcela de seus requisitos, correspondente à parcela de perdas, sobre a qual não têm qualquer controle.

Os balanços de sobra e/ou déficits de cada agente é feito com base nas informações no centro de gravidade do submercado. Desse modo, a parcela de perda alocada aumenta a necessidade de compra dos agentes de consumo e reduz na mesma proporção, a disponibilidade de energia dos agentes de geração.

Como conseqüência da norma que especifica o centro de gravidade como referência para as transações de energia, no processo de cálculo da geração e da carga dos agentes de mercado as respectivas parcelas de perda de transmissão são acrescentadas, ou deduzidas da energia efetivamente consumida ou gerada. O rateio das perdas interfere nos resultados esperados pelos agentes do mercado, atribuindo incertezas adicionais à comercialização de energia entre os mesmos.

A Fig. 8 ilustra o processo de determinação da carga de um agente de consumo e do balanço de energia que ele apresenta no mercado de curto prazo. A carga própria, medida na fronteira do agente de consumo com a rede básica, compõe-se da energia consumida pelos clientes $(C N S)$ e pelas perdas de distribuição $(P D)$, técnicas e comerciais. O "requisito"no centro de gravidade é a soma da carga própria com a parcela de perda de transmissão $(P T)$ alocada ao agente pelo critério de rateio de perdas.



Figura 8: Balanço de Energia de um Agente de Consumo

Para atendimento ao requisito no centro de gravidade, o agente dispõe de contratos de compra de energia de longo prazo $(C L P)$ e de curto prazo $(C C P)$. Na situação (1), ilustrada na Fig. 8, há sobra de energia contratada e essa sobra é vendida pelo agente ao preço da energia no mercado de curto prazo $(C C E E)$. Na situação (2), há déficit de energia contratada e a necessidade adicional será comprada pelo agente ao preço da energia no mercado de curto prazo. O ganho obtido pelo agente de consumo ( $B C$ ) é dado pela equação (18), a seguir.

$$
\begin{aligned}
& B C=(V-C) * P L D- \\
& \quad[(C L P-V L P) * P L P+(C C P-V C P) * P C P]
\end{aligned}
$$

Onde:

- $V$ é a venda de energia no mercado de curto prazo, quando se verifica a situação (1), em MWh;

- $C$ é a compra de energia no mercado de curto prazo, quando se verifica a situação (2), em MWh; 
- $P L D$ é o preço da energia no mercado de curto prazo, em R\$/MWh;

- $C L P$ é a energia adquirida em contratos de longo prazo, em MWh;

- VLP é a energia vendida em contratos de longo prazo, em MWh;

- PLP é o preço praticado pela comercialização de energia em contratos de longo prazo, em $\mathrm{R} \$ \mathrm{MWh}$;

- $C C P$ é a energia adquirida em contratos de curto prazo, em MWh;

- $V C P$ é a energia vendida em contratos de curto prazo, em MWh;

- $P C P$ é o preço praticado pela comercialização de energia em contratos de curto prazo, em $\mathrm{R} \$ / \mathrm{MWh}$.

Para um agente de produção, ou de geração, a Fig. 9 ilustra o processo de cálculo da energia gerada comercializada no âmbito do mercado de curto prazo.

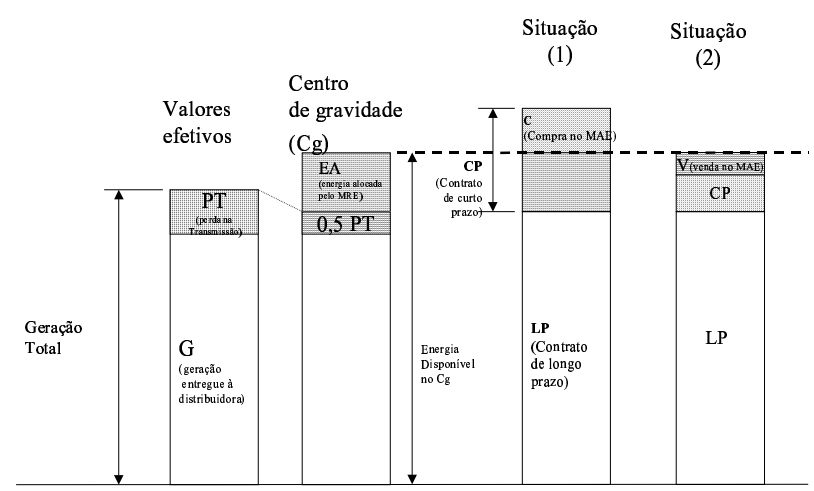

Figura 9: Balanço de Energia de um Agente de Produção

$\mathrm{O}$ total de geração é igual a energia entregue às distribuidoras $(G)$, acrescida das perdas de transmissão $(P T)$. Para referir a geração ao centro de gravidade do sistema, deduz-se a parcela de $50 \%$ das perdas de transmissão e acrescenta-se a parcela de energia $(E A)$ recebida através do mecanismo de realocação de energia - $M R E$ (MAE, 2000).

Admitindo-se que o agente de produção forneça energia através dos contratos que firma com outros agentes, uma vez verificada a situação (1) da Fig. 9, o agente precisa comprar parte da energia requerida (c), pagando o preço do mercado de curto prazo. Se a situação (2) se verificar, o agente venderá energia ao mercado de curto prazo, recebendo o preço desse mercado pela parcela (v) vendida. Assim, o ganho do agente de produção é dado pela equação (19), a seguir.

$$
\begin{gathered}
B P=(V-C) * P L D+[(V L P-C L P) * P L P+ \\
(V C P-C C P) * P C P+ \\
(V M R E-C M R E) * P M R E]
\end{gathered}
$$

Onde:

- $V$ é a venda de energia no mercado de curto prazo, quando se verifica a situação (2), em MWh;

- $C$ é a compra de energia no mercado de curto prazo, quando se verifica a situação (1), em MWh;

- $P L D$ é o preço da energia no mercado de curto prazo, em R $\$ / M W h$;

- VLP é a energia vendida em contratos de longo prazo, em MWh;

- PLP é o preço praticado pela comercialização de energia em contratos de longo prazo, em R $\$ / M W h$;

- $V C P$ é a energia vendida em contratos de curto prazo, em MWh;

- $P C P$ é o preço praticado pela comercialização de energia em contratos de curto prazo, em $\mathrm{R} \$ / \mathrm{MWh}$;

- VMRE é a energia vendida no MRE, em MWh;

- $C M R E$ é a energia comprada no MRE, em MWh;

- $P M R E$ é o preço da energia nas trocas entre geradores pertencentes ao MRE, em R $\$ / M W h$.

\section{ANÁLISE DE RISCO}

Toda instituição que dispõe de uma carteira (portfolio) de ativos financeiros, entre os quais podem ser considerados os contratos de compra e venda de energia, necessita ferramentas consistentes de análise de risco, para buscar a proteção (hedge) necessária. Existem vários mecanismos de medida do risco (Hull, J.C. - 2002), através dos quais instituições financeiras diariamente calculam parâmetros que lhes permitam "medir"a exposição a que estão sujeitas, avaliando cada variável de mercado que interfere no valor das suas carteiras de ativos.

Dentre os processos de avaliação utilizados para subsidiar a tomada de decisão por gerenciadores de carteiras, destacase o Value-at_Risk [VaR]. Através deste método traduz-se o efeito de todas as variáveis de risco do mercado em um único parâmetro, capaz de sinalizar a exposição global da carteira. 
O cálculo do VaR tem se mostrado consistente nas aplicações práticas das instituições financeiras e se tornado cada vez mais difundido entre empresas de gestão de fundos. A aceitação dessa metodologia de análise de risco motivou a adoção dos conceitos envolvidos no cálculo do Value-at-Risk neste trabalho. Para isso, propõe-se que as alternativas de contratação de energia ou as possibilidades de investimento em ativos do setor elétrico sejam tratados como ativos financeiros.

Formalmente, o "Valor em Risco" (VaR) define o mínimo de ganho, ou o máximo de perda, que se espera ter em uma carteira de ativos, com uma dada probabilidade. Assim, se "tudo der errado" durante um período de tempo t, o VaR é o ganho mínimo que se espera da carteira, com a probabilidade definida pelo gestor da carteira. Nos casos práticos utiliza-se normalmente a probabilidade de $95 \%$.

Se para um determinado conjunto de cenários de preços de mercado o resultado da carteira de ativos puder ser representada por uma função densidade de probabilidades, o VaR será o ponto dessa função com probabilidade $5 \%$ de não ser superada; ou seja, a probabilidade de que o resultado da carteira seja superior ao VaR é 95\%. A Fig. 10 mostra a representação do VaR para uma função densidade de probabilidade próxima à função normal.

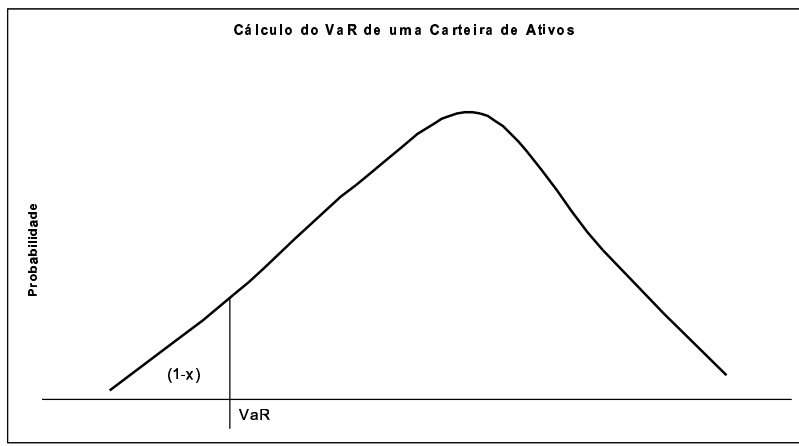

Figura 10: Representação gráfica do Value-at-Risk (VaR)

A alternativa de usar o VaR em decisões sob riscos é atraente quando as empresas conseguem se posicionar no mercado visando sempre o máximo VaR, com valores positivos deste parâmetro, de tal forma que a expectativa do decisor será a obtenção de um ganho na transação, mesmo que "tudo possa dar errado". Essa alternativa, no entanto, não é viável para as empresas de energia elétrica, que comercializam uma mercadoria considerada de serviço público, essencial para o desenvolvimento de toda a economia do País.

Para atender às regulamentações próprias do setor elétrico, os agentes desse mercado são muitas vezes obrigados a fazer investimentos que apresentam VaR negativo, os quais jamais seriam feitos em situação de maior liberdade (Artzner, et alli,
2004; Castro, 2004).

Assim, neste trabalho optou-se por representar a função densidade de probabilidade dos ganhos financeiros esperados, por um conjunto de pontos notáveis dessa função e não apenas pelo VaR. Os pontos utilizados, serão o ponto que é superado com $95 \%$ de probabilidade (M1), o ponto médio (M2), o ponto que apresenta $5 \%$ de probabilidade de ser superado (M4) e o ponto que representa a moda (M3) da função densidade de probabilidade dos resultados.

Os pontos notáveis, são associados em uma combinação convexa para determinar uma medida da qualidade das decisões, discutida no próximo item. Esta forma de associação visa também, traduzir a percepção e a aversão ao risco, adotadas no processo de tomada de decisões.

\section{MÉTRICA PARA A QUALIDADE DAS DECISÕES}

Se um agente do setor elétrico que adotar o ponto da função densidade de probabilidade superado com $95 \%$ de probabilidade (M1) como a única medida para tomar suas decisões apresenta um perfil conservador, pois está preocupado em minimizar o prejuízo. Não busca aproveitar as chances de lucro que as alternativas podem apresentar.

O decisor que busca a maximização deste ponto da função, procura a alternativa representada por $\mathrm{a}^{*}$ na Fig. 11.

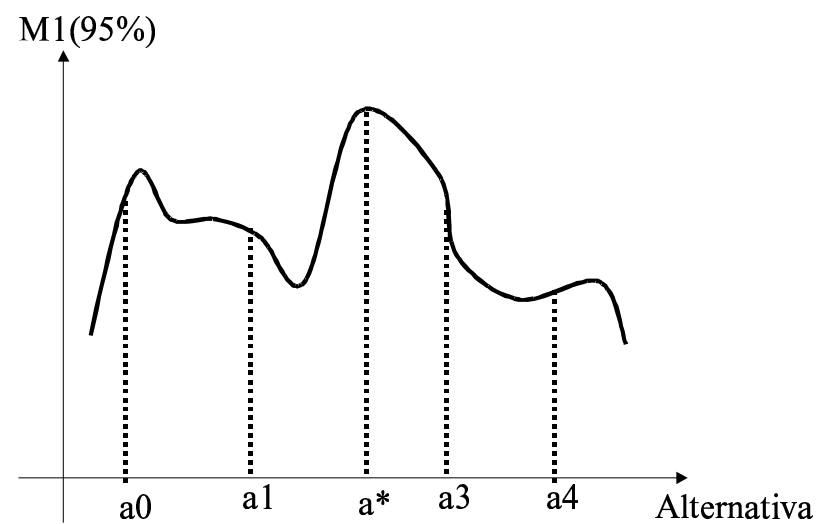

Figura 11: Alternativa ótima sob a ótica do ponto notável M1

Por outro lado, se o único parâmetro de decisão adotado for o ponto complementar a M1, ou seja, o ponto com probabilidade 5\% de ser superado (M4), o decisor apresenta um perfil extremamente afeto ao risco, apostando sempre na chance de ganhar o máximo possível, mesmo que a chance de ganho seja remota. Sua escolha é a alternativa de maior retorno possível com probabilidade de ocorrência de 5\%, independente da probabilidade de prejuízo. 
Na Fig. 12 a seguir ilustra-se a alternativa ótima do problema para o decisor que avalia o ganho que pode auferir com probabilidade de $5 \%$.

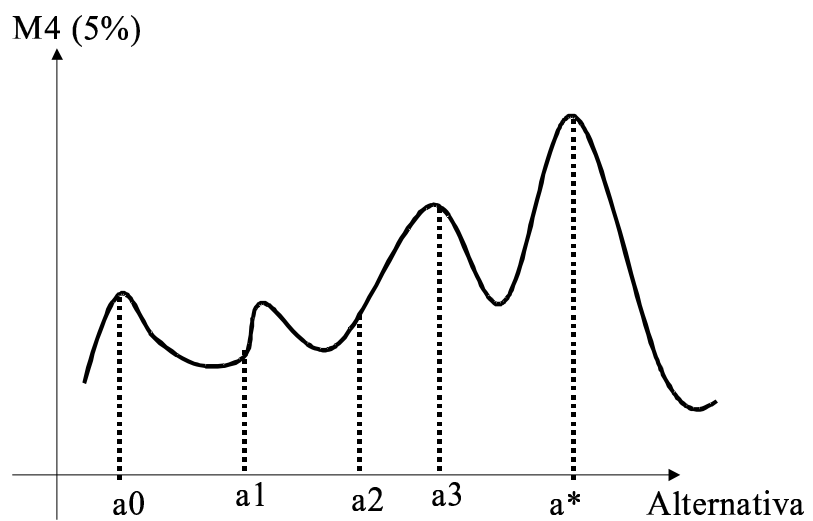

Figura 12: Alternativa ótima sob a ótica do ponto M4

Se o decisor utiliza a média da função distribuição de probabilidades está buscando equilíbrio entre a probabilidade de ganho e a probabilidade de perda em suas decisões. Aposta na redução da diferença entre o resultado que buscou e o resultado obtido com suas decisões.

A moda da distribuição seria o parâmetro utilizado pelo decisor que visa exclusivamente o retorno mais provável dentre as alternativas disponíveis, optando pela alternativa que apresenta o maior retorno no ponto de máxima probabilidade.

Observa-se que cada decisor definiria uma solução diferente, pelo fato de ter se utilizado de um parâmetro distinto no processo de tomada de decisão e por apresentar diferente percepção do risco do negócio.

Na prática, no entanto, é mais provável que se encontrem decisores que não possam ser situados exatamente em nenhum dos perfis discutidos anteriormente. É razoável supor que cada um tenha um pouco de cada característica, buscando simultaneamente minimizar o prejuízo provável, maximizar o ganho esperado, reduzir a diferença entre o resultado esperado e o realizado, enquanto aposta na maior chance que tem de auferir bons resultados.

Esta é uma característica típica de um problema multiobjetivo (ou multicritério), onde busca-se simultaneamente maximizar os resultados de diversas funções objetivo do problema. Para esses problemas busca-se definir o conjunto de soluções eficientes, caracterizado pela curva de trade-off do problema. No item a seguir discute-se os conceitos básicos envolvidos com a otimização multiobjetivo, associado-se tais conceitos à solução do problema de decisão.

\subsection{Otimização Multiobjetivo}

Os conceitos básicos envolvidos na otimização multicritério (ou multiobjetivo) são as soluções eficientes e as curvas de trade-off (Castro, 1994; Lyra, Castro \& Ferreira, 1995; Chankong, \& Haimes, 1983; Chankong et al, 1981).

Uma solução $x^{*}$ do problema multicritério é uma solução eficiente se qualquer outra solução $\mathrm{x}$ que melhore uma das funções objetivo do problema levar, necessariamente, à degradação de pelo menos uma das demais funções objetivo. A Fig. 13 ilustra o conjunto de soluções eficientes para um problema com duas funções objetivo.

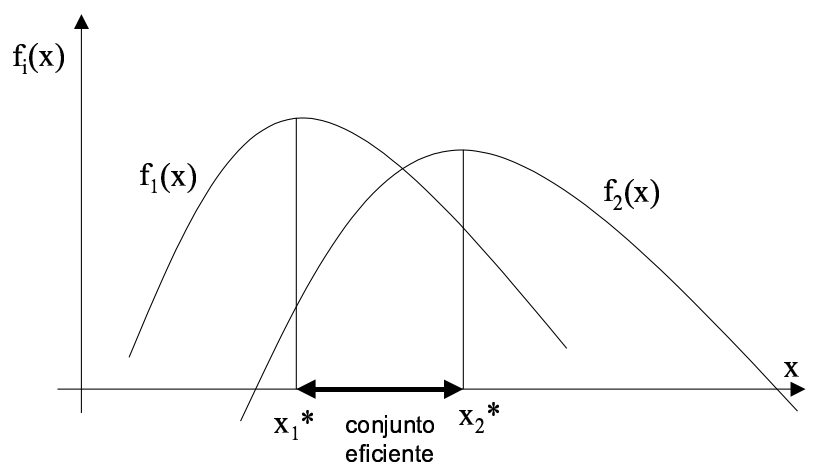

Figura 13: Representação do conjunto eficiente

Observe-se que para as soluções inferiores a $\mathrm{x}_{1} *$ e superiores $\mathrm{a}_{2}$ * é possível encontrar soluções que melhoram ou pioram simultaneamente ambas as funções objetivo. No conjunto eficiente, entre $\mathrm{x}_{1} * \mathrm{e}_{2} *$, qualquer solução que melhore uma das funções, necessariamente degrada a outra função.

Os valores das funções objetivo para o conjunto das soluções eficientes do problema definem a curva de trade-off que é a imagem das soluções eficientes no espaço das funções objetivo. Na Fig. 14 ilustra-se a curva de trade-off de um problema com duas funções objetivo.



Figura 14: Curva de trade-off

Se a curva apresentada na Fig. 14 corresponde ao problema 
multiobjetivo da Fig. 13, o ponto A e o ponto B são os pontos extremos da curva de trade-off e representam, respectivamente, os valores das funções objetivo nos pontos $\mathrm{x}_{1} * \mathrm{e}$ $\mathrm{x}_{2} *$.

Um dos métodos mais usados para solução de problemas multiobjetivo é o método dos pesos (Chankong, \& Haimes, 1983), que consiste em atribuir ponderações a cada função objetivo do problema convertendo-o em problema com objetivo único.

Demonstra-se que sob condições de "bom comportamento"das funções, a solução ótima do problema ponderado, definido a partir da combinação convexa das funções objetivo originais do problema, é uma solução eficiente do problema original (Chankong, \& Haimes, 1983). Na equação (20) a seguir, define-se a função objetivo ponderada para o problema de duas funções objetivo.

$$
F(x)=w f_{1}(x)+(1-w) f_{2}(x) ; w \in(0,1)
$$

Onde,

- $F(x)$ é a função objetivo única do problema ponderado;

- $f_{1}(x)$ e $f_{2}(x)$ são as funções objetivo originais do problema;

- $w$ é o fator de ponderação.

A equação (20) pode ser generalizada para um número maior de funções. Nesse caso, pontos da superfície de trade-off podem ser obtidos por combinações convexas das funções. Essa idéia sugere uma alternativa para considerar simultaneamente os vários objetivos discutidos anteriormente, envolvendo o processo de tomada de decisões no setor elétrico. Este aspecto será discutido no item a seguir.

\subsection{Aproximação da curva de trade-off}

Em princípio, partes significativas da superfície de trade-off para decisões no setor elétrico podem ser obtidas por uma combinação convexa de todo o elenco de funções objetivo. Assim, cada ponto dessa superfície é obtido pela maximização da função objetivo expressa pela combinação convexa, conforme apresentado a seguir.

$$
\begin{gathered}
W=\alpha_{1} M 1+\alpha_{2} M 2+\alpha_{3} M 3+\alpha_{4} M 4 \\
\sum \alpha_{i}=1
\end{gathered}
$$

Onde,

- $W$ é a função objetivo ponderada do problema [R \$;

- $M 1$ é o ponto da função densidade de probabilidade que determina o resultado esperado pelo decisor com $95 \%$ de probabilidade de ser superado [R $\$$;

- M2 é o ponto da função densidade de probabilidade que determina o resultado esperado pelo decisor com $50 \%$ de probabilidade (ponto médio da fdp) [R $\$$;

- M3 é o ponto da função densidade de probabilidade que determina o resultado esperado pelo decisor com máxima probabilidade de ocorrer (moda da distribuição) $[\mathrm{R} \$$;

- M4 é o ponto da função densidade de probabilidade que determina o resultado esperado pelo decisor que é superado com probabilidade $5 \%[\mathrm{R} \$$;

- $\alpha_{i} i=1,2,3,4$, são os multiplicadores definidos pela combinação convexa dos pontos da função densidade de probabilidade [adimensional].

A combinação das soluções delimita a área do politopo convexo formado pelos pontos notáveis. Cada ponto pertencente a este politopo apresenta uma certa graduação da aversão que o decisor tem ao risco. A Fig. 15, ilustra a combinação convexa dos pontos notáveis da função. A graduação de cores foi adotada para mostrar os pontos que seriam escolhidos pelo decisores com maior propensão ao risco.

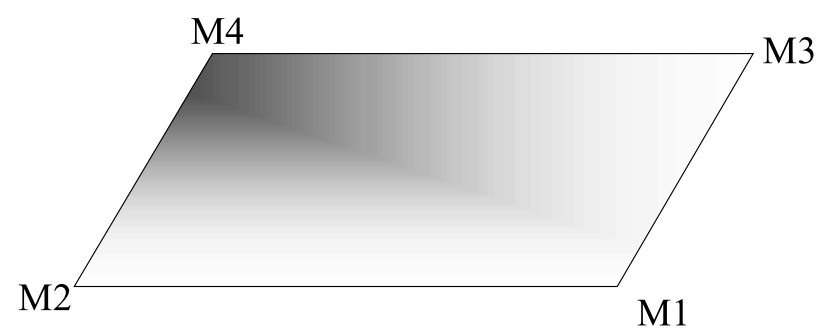

Figura 15: Politopo originado pela combinação convexa

A caracterização dos parâmetros $\alpha_{i}$ pode ser vista como uma forma de abordar um problema multicritério. Deve-se observar, no entanto, que as funções objetivo que compõem a combinação convexa $W$ definida na equação (21) não são funções "bem comportadas". Assim, não há garantia formal de que os pontos obtidos pela maximização da função $W$ pertençam ao conjunto de soluções eficientes do problema. Em outras palavras, não há garantia de que a imagem desses pontos no espaço das funções objetivo pertençam à superfície de trade-off do problema. 
As soluções eficientes (ou de Pareto) de problemas multiobjetivo convexos podem ser obtids de forma completa, levando conforto para o decisor na solução do problema.

Não se pode garantir que as funções que definem os pontos $M 1, M 2, M 3$ e $M 4$, conforme proposto neste trabalho através da equação (21) sejam funções convexas e portanto, não se pode garantir que as soluções geradas pelo método possam ser utilizadas nos casos reais de tomada de decisão sem os devidas análises sobre a solução apresentada.

Entretanto, na análise de sensibilidade que se apresenta no estudo de caso descrito no item 6 , observa-se que para um conjunto extenso de multiplicadores $\alpha_{i}$, as soluções apresentadas são coerentes, descartando-se a alternativa dominada em todas as hipóteses.

Esta análise de sensibilidade aliada ao conhecimento que os tomadores de decisão têm sobre o problema de comercialização de energia no setor elétrico brasileiro, trazem o conforto necessário para que as soluções apresentadas pela metodologia possam ser consideradas no processo de tomada de decisão.

Remete-se ao desenvolvimento futuro do método apresentado, a investigação teórica sobre a convexidade das funções tratadas no problema, bem como os impactos que a não convexidade dessas funções podem trazer aos resultados esperados.

Os pontos obtidos com a maximização da função $\mathrm{W}$ devem ser interpretados como uma aproximação do conjunto de soluções eficientes. Por isso, é imperativo que sejam realizadas análises de sensibilidade sobre as soluções obtidas, para atribuir maior credibilidade no processo de tomada de decisões.

No item a seguir apresenta-se uma aplicação prática do método. Os dados utilizados no estudo de caso são extraídos de situações reais para um empresa do setor elétrico brasileiro atuando na área de distribuição de energia.

\section{ESTUDO DE CASO}

Neste item apresenta-se a aplicação do método proposto para um estudo de caso, baseado em dados reais para o setor elétrico brasileiro. Mostra-se uma empresa distribuidora de energia elétrica buscando contratar energia para um período de 24 meses.

\subsection{Cenários de preço no mercado de curto prazo}

Utilizando-se um cenário de oferta de energia e de evolução do mercado, na Fig. 16 apresenta-se o valor esperado do preço no mercado de curto prazo de energia, em função da afluência esperada para o sistema ao longo de 24 meses.

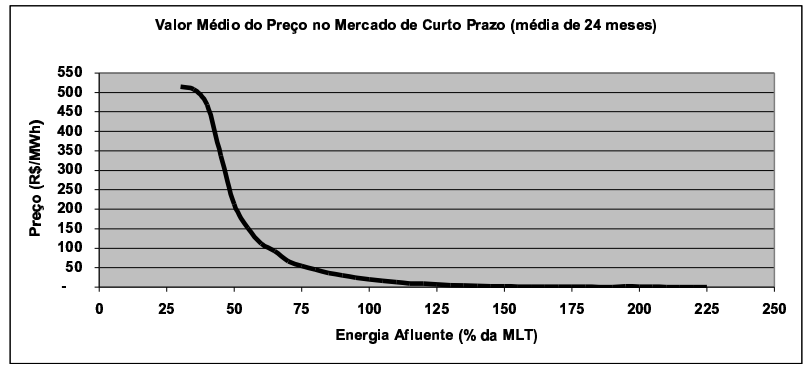

Figura 16: Expectativa de preço função da Energia Afluente

As probabilidades associadas às afluências esperadas no horizonte de estudo são apresentadas na Fig. 17 a seguir.

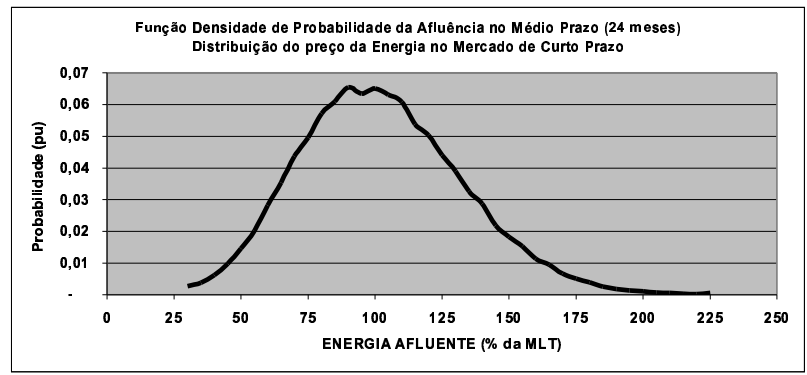

Figura 17: Probabilidade da Energia afluente

\subsection{Alternativas de contratação}

As alternativas de contratação de energia são consideradas em termos de percentagem dos requisitos de energia. Para esse estudo de caso, considerou-se a contratação mínima de 95\% do requisito. Sob essas hipóteses foram geradas as seguintes alternativas de contratação:

i) Alternativa base (Alt95\%): Manter a contratação mínima durante todo o período;

ii) Alternativa 1 (Alt97\%): Contratar 97\% dos requisitos durante todo o período;

iii) Alternativa 2 (Alt98,8\%): No horizonte de análise, durante os meses de seca, contratar $100 \%$ das necessidades, durante os meses úmidos, contratar $97 \%$ do requisito;

iv) Alternativa 3 (Alt100\%): Contratar $100 \%$ dos requisitos durante todo o período de análise;

v) Alternativa 4 (Alt100,8\%): Durante os meses secos do horizonte, contratar $105 \%$ dos requisitos e durante os meses úmidos, manter a contratação mínima de $95 \%$; 
vi) Alternativa 5 (Alt105\%): Manter contratação de $105 \%$ dos requisitos durante todo o horizonte de estudo.

A Fig. 18 a seguir mostra a energia contratada mensalmente de acordo com as alternativas consideradas.



Figura 18: Alternativas de contratação

O prazo de maturação de um empreendimento para geração de energia elétrica é o período de tempo transcorrido entre o início da sua construção e a data em que a usina começa a gerar eletricidade.

O prazo de maturação dos projetos varia com o tipo de usina. Geralmente as usinas hidrelétricas têm maturação mais longa do que as termelétricas, motivo pelo qual, exigem previsão de mais longo prazo da evolução da demanda para entrarem em operação.

Visando estabelecer condições favoráveis ao desenvolvimento da oferta, a regulação do setor (lei 10.848 e decreto 5.163) definem a necessidade de contratação da totalidade da carga, com antecedência mínima de 5 e 3 anos da data prevista do consumo.

Para atender à obrigatoriedade de contratação mínima, questão que até o momento ainda não foi regulamentada no setor elétrico, deverá ser considerado um período de 12 meses na apuração do lastro contratual.

Assim, mesmo as alternativas de contratação que representem compra abaixo de $100 \%$ do requisito, exigido pela legislação, podem ser adotadas na prática, desde que observada a contratação mínima durante o período de apuração que será definido na regulamentação do assunto.

Além disso, a contratação de energia no ambiente de contratação regulado pode ser ajustado em leilões que antecedem em 5, 3 e 1 ano a data de consumo. No ambiente de contratação livre, as contratações bilaterais podem ser ajustadas continuamente, se assim o agente o desejar.

Desse modo, para utilização do método proposto neste trabalho, em situações práticas (reais), recomenda-se que as al- ternativas avaliadas sejam formuladas de modo a atender simultaneamente à expectativa que o agente tem do mercado e às restrições de comercialização impostas pela legislação vigente.

\subsection{Função Densidade de Probabilidade dos Resultados Financeiros}

Considerando os cenários do preço da energia no mercado de curto prazo e as alternativas de contratação de energia avaliadas nesse estudo de caso, a Fig. 19 apresenta a função densidade de probabilidade dos resultados financeiros obtidos pelo agente, a partir da aplicação do método de estimativa dos resultados apresentados no item 3 .

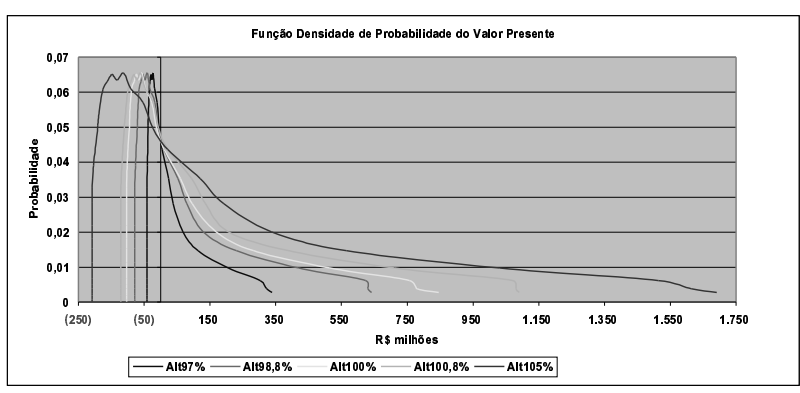

Figura 19: Função densidade de probabilidade dos resultados financeiros

Note-se que para todas as alternativas avaliadas, o ponto que apresenta probabilidade $95 \%$ de ser superado (M1) apresenta valor negativo, indicando que contratação de $95 \%$ de todo o requisito é uma restrição que representa expectativa de perda financeira para os cenários de preço futuro da energia, qualquer que seja a decisão de contratação adotada.

Os valores da função densidade de probabilidade nos pontos notáveis são apresentados na Tabela 1 a seguir.

Tabela 1: Valores em R $\$$ milhões

\begin{tabular}{|c|r|r|r|r|r|}
\hline Ponto & Alt97\% & Alt98,8\% & Alt100\% & Alt100,8\% & Alt105\% \\
\hline M1(95\%) & $(41,63)$ & $(78,07)$ & $(104,07)$ & $(121,46)$ & $(208,14)$ \\
\hline Moda & $(22,45)$ & $(40,64)$ & $(56,13)$ & $(60,61)$ & $(112,26)$ \\
\hline Média & $(28,42)$ & $(51,79)$ & $(71,05)$ & $(77,90)$ & $(142,10)$ \\
\hline M4(5\%) & 83,88 & 165,35 & 209,71 & 271,54 & 419,42 \\
\hline
\end{tabular}

Note-se que para a alternativa de contratação mínima constante de $95 \%$ do requisito não foram levantados os pontos notáveis da curva. Essa é a alternativa que representa o o caso base de contratação adotada neste estudo de caso, não sendo portanto, objeto de análise de decisão, mas apenas considerado como referência para avaliação dos resultados dos demais casos. 


\subsection{Tomada de decisão}

Os multiplicadores dos parâmetros definidos pela função densidade de probabilidade são definidos pela aplicação dos conceitos de otimização multiobjetivo, que associa a aversão ao risco do decisor aos multiplicadores. Seja um conjunto de quatro diferentes decisores, com aversões ao risco distintas entre si.

A Tabela 2 apresenta a sensibilidade sobre os multiplicadores $\alpha_{i}$ que se ajustam aos diferentes perfis de aversão ao risco. Observa-se, que o decisor 1 tem maior aversão ao risco e o decisor 4 tem a maior atração ao risco dentre todos eles.

Tabela 2: Sensibilidade sobre os multiplicadores $\alpha_{i}$ para os diversos decisores

\begin{tabular}{|c|c|c|c|c|}
\hline & \multicolumn{4}{|c|}{ Decisor } \\
\hline & $\mathbf{1}$ & $\mathbf{2}$ & $\mathbf{3}$ & $\mathbf{4}$ \\
\hline alfa1 & 1,0 & 0,1 & 0,4 & 0,0 \\
\hline alfa2 & 0,0 & 0,3 & 0,1 & 0,0 \\
\hline alfa3 & 0,0 & 0,5 & 0,2 & 0,0 \\
\hline alfa4 & 0,0 & 0,1 & 0,3 & 1,0 \\
\hline
\end{tabular}

Resolvendo-se o problema definido em (21), determinam-se os valores de $\mathrm{W}$ para cada decisor tendo em vista cada alternativa de contratação de energia. Os resultados são apresentados na Tabela 3 .

Tabela 3: Resultados do processo de tomada de decisão

\begin{tabular}{|l|r|r|r|r|r|r|}
\cline { 2 - 7 } \multicolumn{1}{c|}{} & Alt95\% & \multicolumn{1}{c|}{ Alt97\% } & Alt98,8\% & Alt100\% & Alt100,8\% & Alt105\% \\
\hline Decisor 1 & 0,00 & $(41,63)$ & $(69,68)$ & $(78,91)$ & $(37,58)$ & $(208,14)$ \\
\hline Decisor 2 & 0,00 & $(16,72)$ & $(29,36)$ & $(41,80)$ & $(42,13)$ & $(83,60)$ \\
\hline Decisor 3 & 0,00 & 0,58 & 3,96 & 1,46 & 11,24 & 2,92 \\
\hline Decisor 4 & 0,00 & 83,88 & 165,35 & 209,71 & 271,54 & 419,42 \\
\hline
\end{tabular}

Para os resultados obtidos, a opção dos decisores 1 e 2 seria não contratar energia além do mínimo obrigatório. $\mathrm{O}$ decisor 3 optaria pela alternativa de contratação de $100,8 \%$ e o decisor 4 optaria pela contratação de $105 \%$ dos requisitos de energia.

\section{CONCLUSÃO}

O modelo de mercado do qual resultaram as regras impostas para os agentes do setor elétrico brasileiro sofreu alterações substanciais a partir de meados dos anos 90 .

A partir de 1995, com a promulgação da lei 9074, a qual impôs regras para a concorrência pela concessão nos serviços públicos de energia elétrica e abriu espaço para o processo de privatização, o modelo para o setor migrou para as regras de mercado livre.

Atualmente, a partir da promulgação da lei 10.848 , há uma expectativa de que os novos rumos do setor elétrico sejam norteados por políticas públicas e por regulação que restrinjam o crescimento do livre mercado, embora preservem o ambiente livre de comercialização para uma parcela do mercado, e limitem o tratamento da energia elétrica como mercadoria passível de livre comercialização. Em ambos os casos, na situação atual do setor elétrico, ou em expectativa futura mais restritiva à comercialização, os riscos de investimentos e de contratação de energia são inerentes ao setor elétrico. Assim, os tomadores de decisão não devem prescindir de ferramentas adequadas para suportarem suas posições.

O método apresentado neste trabalho é um processo de suporte à tomada de decisão sob risco que permite avaliar os resultados financeiros esperados pelo decisor, levando em conta seu perfil de aversão ao risco e pode ser utilizado mesmo em modelo alternativo para o mercado de energia elétrica que se adote no Brasil, onde por maiores restrições que se imponham ao livre mercado, as necessidades de contratação de energia e de investimento na expansão, associadas às incertezas inerentes às expectativas de consumo de energia elétrica, estabelecem um cenário de risco que deve ser tratado por métodos qualitativos apropriados.

O Método é aplicável para decisões de investimento ou de contratação de energia no mercado compra e venda no atacado, bem como na definição de um processo continuado de avaliação do portfólio dos ativos que envolvem a energia elétrica em uma empresa, seja distribuidora, geradora, comercializadora ou cliente final. Ou seja, pode-se aplicar a metodologia apresentada neste trabalho em qualquer negócio que envolva energia elétrica cujo retorno depende do preço da energia no mercado de curto prazo, especialmente aos negócios feitos no âmbito do ambiente de contratação livre.

As principais contribuições deste trabalho podem ser resumidas nos pontos a seguir.

Desenvolvimento de método para estimativa de preço da energia em horizonte de médio prazo;

Detalhamento do método de cálculo dos resultados financeiros dos agentes de mercado de energia elétrica no País;

Proposta de utilização no setor elétrico de procedimentos para análise e gerenciamento de riscos, utilizados com sucesso por instituições financeiras;

Incorporação da teoria das decisões multicritério ao conjunto de ferramentas que os decisores do setor elétrico dispõem atualmente.

Os riscos inerentes à expansão da oferta de energia no sistema são o déficit, que compromete o crescimento do País e a sobra de energia, quando o programa de expansão fica acima das necessidades do mercado. Se por um lado, o déficit tem 
efeitos devastadores, o excesso de investimento que ocasiona a sobra de energia, representa um custo elevado para a sociedade; particularmente, para os consumidores de energia elétrica.

Por utilizar o CMO no processo de cálculo, o método proposto neste trabalho permite que um decisor envolvido na expansão da oferta adeque seus investimentos à situação de preço que lhe for mais favorável.

A precificação adequada da energia comercializada pelas empresas é outro fator decisivo no sucesso do plano de expansão. Ajustando-se a oferta às necessidades do mercado, através da remuneração justa dos investidores, a expectativa de desajustes na oferta e demanda (déficits ou sobras) é minimizada.

Intuitivamente um gerador que dispõe de maior flexibilidade no atendimento à carga deve receber mais pela energia que gera do que um outro gerador que fornece energia sem a flexibilidade requerida pelo mercado. Determinar o quanto mais deve ser pago pela energia é objeto de avaliação das condições do mercado e das expectativas do preço futuro.

Para avaliar situações dessa natureza, recomenda-se que o método proposto neste trabalho seja complementado por um processo de precificação da energia que permita aos decisores determinarem os preços que devem ser cobrados e pagos pela energia em diferentes situações de flexibilidade oferecida ao mercado.

Uma alternativa para definição dos multiplicadores $\alpha_{i}$, levando em conta o caráter mais normativo da decisão, seria a adaptação de técnicas de inteligência artificial (Russel \& Norvig, 1995) para dinamicamente ajustar tais multiplicadores no tempo, de acordo com a expectativa de evolução dos preços e dos resultados esperados, considerando o perfil de aversão ao risco apresentado pelo decisor e simultaneamente, aspectos estruturais do setor elétrico.

\section{AGRADECIMENTOS}

Christiano Lyra Filho agradece o apoio do Conselho Nacional de Desenvolvimento Científico e Tecnológico, $\mathrm{CNPq}$

\section{REFERÊNCIAS}

Amundsen, E. S.; Bjorndalen, J.; Rasmussen, H. - "Export of Norwegian hydropower under a common European regime of environmental taxes". Energy Econ., vol 16 1994.

Anderson, B.; Bregman, L.; - "Market Structure and the Price of Electricity: An ex-ante analysis of the deregulated Swedish electricity market ". Energy J., vol. 16 - 1995.
Artzner, P; Delbaen, F; Eber, J \& Heath, D - "Thinking Coherently", 2004.

Biblioteca do Exército - "A energia elétrica no Brasil - da primeira lâmpada à Eletrobrás". Rio de Janeiro/RJ, 1977 (OBS: O autor não está identificado na publicação)

Brebnnan, D.; Melanie, J. - "Market powering the Australian power market". Energy Econ. Vol 20 - 1998.

California Independent System Operator (2000): www.caliso.com

Caramanis, M.C. - "Investment decisions and long-term planning under electrical spot pricing". IEEE Transactions on Power Apparatus Systems, vol. 101 - dezembro de 1982.

Castro, R. - "Análise de decisões sob incertezas para investimentos e comercialização de energia elétrica no Brasil”. Tese de doutorado, FEEC/UNICAMP, 2004

Castro, R.; Lyra, C. "Um método para estimativa do preço da energia no mercado atacadista no horizonte de médio prazo". XVII SNPTEE - Seminário Nacional de Produção e Transmissão de Energia Elétrica - 2003.

Castro, R. - "Dimensionamento de usinas hidroelétricas considerando objetivos múltiplos na utilização da água". Tese de Mestrado. Faculdade de Engenharia Elétrica e de Computação da Universidade Estadual de Campinas - FEEC/UNICAMP, março de 1994.

Castro, R., Ramos, D. S., Lyra, C. - "Comercialização de energia no ambiente competitivo do setor elétrico brasileiro". XV SNPTEE - Seminário Nacional de Produção e Transmissão de Energia Elétrica, 1999.

Cepel - "Programação Dinâmica Dual Estocástica aplicada ao Planejamento da Operação Energética de Sistemas Hidrotérmicos com Representação do Processo Estocástico de Afluências po Modelos Auto-regressivos Periódicos". Relatório técnico 237/93 - 1993.

Chankong, Vira e Haimes, Yacov Y. - "Multiobjective decision making - Theory and methodology". NorthHolland . New York - Amsterdam - Oxford.

Chankong, V.; Haimes, Y. Y. \& Gemperline, D. M. - "A multiobjective dynamic programming method for capacity expansions."IEEE - Transactions on Automatic Control AC-26(5), 1195-1207.

Cláusula Ouro - Decreto 23.501 de 27 de novembro de 1933.

Código de Águas - Decreto 24.643 de 10 de julho de 1934. 
Davidson, M.; Andersen, C. L.; Marcus, B.; Anderson, K. - "Development of a hybrid model for electrical power spot prices". IEEE Transactions on powerr Systems vol. 17, n. 2 - maio de 2002.

Decreto 4562 - Presidência da República - Dezembro de 2002.

Hull, J. C. - "Options, Futures, \& others Derivatives- 5a edição, Prentice Hall, 2002.

Kall, P.; Wallace, S. W. - "Stochastic Programming" - John Wiley \& Sons, 1994.

Lyra, C.; Castro, R.; Ferreira, L.R.M. - "Assessing decision on multiple uses of water and hydroelectric facilities". London Business School. International Symposium on Energy Models. Londres, 1995.

MAE - "Visão Geral das Regras de Mercado - etapa de Implantação- Mercado Atacadista de Energia (MAE), setembro de 2000.

Martinez, L. - "Políticas de Controle Malha Fechada e Malha Aberta no Planejamento da Operação Energética de Sistemas Hidrotérmicos- Tese de Doutorado/FEEC Unicamp - setembro de 2001.

Mininstério das Minas e Energia (MME) - "Proposta de modelo institucional do setor elétrico- julho de 2003.

New York Independent System Operator (2000): www.nyiso.com

ONS - "Programa mensal de operação". Online no site do Operador Nacional do Sistema - ONS: www.ons.org.br - maio de 2005.

Paixão, L. E. - "Memórias do projeto Re-Seb- Massao Ohno Editor, 2000.

Pereira, M.V.F. \& Pinto L.M.V.G. - "Multi-stage Stochastic Optimization Applied to Energy Planning". Mathematical Programming 52 - 1991.

Pérez-Arriaga, I.J.; Meseguer, C. - "Wholesale marginal prices in competitive generation markets". IEEE Transations on Power Systems, vol 12 - maio de 1997.

PJM Interconnection LLC (2000): www.pjm.com

Russel, Stuart \& Norvig, peter - "Artificial inteligence - A modern approach.", Prentice Hall, New Jersey, 1995

Vásquez, C.; Rivier M.; Pérez-Arriaga, I.J. - "A market appproach to long-term security of supply". IEEE Transactions on Power Systems, vol 17 n 2 - maio de 2002. 